\title{
REVIEW
}

Open Access

\section{The role and scope of practice of midwives in humanitarian settings: a systematic review and content analysis}

\author{
Kristen Beek ${ }^{1}$, Alison McFadden ${ }^{2^{*}}$ and Angela Dawson ${ }^{1}$
}

\begin{abstract}
Background: Midwives have an essential role to play in preparing for and providing sexual and reproductive health (SRH) services in humanitarian settings due to their unique knowledge and skills, position as frontline providers and geographic and social proximity to the communities they serve. There are considerable gaps in the international guidance that defines the scope of practice of midwives in crises, particularly for the mitigation and preparedness, and recovery phases. We undertook a systematic review to provide further clarification of this scope of practice and insights to optimise midwifery performance. The review aimed to determine what SRH services midwives are involved in delivering across the emergency management cycle in humanitarian contexts, and how they are working with other professionals to deliver health care.

Methods: Four electronic databases and the websites of 33 organisations were searched between January and March 2017. Papers were eligible for inclusion if they were published in English between 2007 and 2017 and reported primary research pertaining to the role of midwives in delivering and performing any component of sexual and/or reproductive health in humanitarian settings. Content analysis was used to map the study findings to the Minimum Initial Service Package (MISP) for SRH across the three phases of the disaster management cycle and identify how midwives work with other members of the health care team.
\end{abstract}

Results: Fourteen studies from ten countries were included. Twelve studies were undertaken in conflict settings, and two were conducted in the context of the aftermath of natural disasters. We found a paucity of evidence from the research literature that examines the activities and roles undertaken by midwives across the disaster management cycle. This lack of evidence was more apparent during the mitigation and preparedness, and recovery phases than the response phase of the disaster management cycle.

Conclusion: Research-informed guidelines and strategies are required to better align the scope of practice of midwives with the objectives of multi-agency guidelines and agreements, as well as the activities of the MISP, to ensure that the potential of midwives can be acknowledged and optimised across the disaster management cycle.

Keywords: Midwives, Task-shifting, Task-sharing, Humanitarian settings, Sexual and reproductive health, Disaster management cycle, Systematic review

\footnotetext{
* Correspondence: a.m.mcfadden@dundee.ac.uk

${ }^{2}$ Mother and Infant Research Unit, School of Nursing \& Health Sciences,

University of Dundee, Scotland, UK

Full list of author information is available at the end of the article
}

(C) The Author(s). 2019 Open Access This article is distributed under the terms of the Creative Commons Attribution 4.0 International License (http://creativecommons.org/licenses/by/4.0/), which permits unrestricted use, distribution, and reproduction in any medium, provided you give appropriate credit to the original author(s) and the source, provide a link to the Creative Commons license, and indicate if changes were made. The Creative Commons Public Domain Dedication waiver (http://creativecommons.org/publicdomain/zero/1.0/) applies to the data made available in this article, unless otherwise stated. 


\section{Introduction}

In 2015, 65.6 million people were forcibly displaced worldwide, with data indicating that more than 125 million people were in need of humanitarian assistance globally [1]. Seventy-five percent of those in need of humanitarian assistance are women and girls, aged 15 to 49 [2]. A lack of access to sexual and reproductive health (SRH) services and information is a leading cause of morbidity and mortality among displaced women and girls of reproductive age [3]. Sixty percent of preventable maternal deaths and $45 \%$ of neonatal deaths take place in displacement settings [4] and more than one in five refugees or displaced women in humanitarian settings experience sexual violence [5] placing them at risk of unplanned pregnancies, HIV and other sexually transmitted infections (STIs).

Motivated healthcare staff able to deliver SRH services are required throughout the health emergency and disaster risk management cycle. Before a crisis, planning and preparation may include working with communities for disaster risk reduction (DRR) and building partnerships, capacity and supply systems. The Minimum Initial Service Package (MISP) for Reproductive Health in $\mathrm{Hu}$ manitarian Settings [6] outlines five objectives, activities and resources to address the SRH needs of people in humanitarian emergencies. In the post-crisis transition and recovery phase, skilled staff are needed to restore and strengthen SRH services to reduce vulnerability to future events [3]. However, there is a global shortage of health workers in general, estimated at 7.2 million in 2013 [7], and of skilled birth attendants in particular. The World Health Report [8] reported a global shortage of 2.4 million midwives, nurses and physicians among 57 countries below the threshold for $80 \%$ coverage of skilled birth attendants. In this context, it is unsurprising that there is also a dearth of skilled health workers during humanitarian crises $[9,10]$. This shortage includes both coverage [9] and lack of health workers with the necessary skills [9-11]. Midwives, trained to international standards and competencies, are associated with improved quality of care and efficient use of resources [12] and can potentially meet some of the shortfall of skilled health workers in humanitarian crises.

The geographic and social proximity of midwives to the communities they serve has the potential to prevent avoidable maternal deaths [13] and has been recognised as a key strength of this cadre. Global momentum toward increasing midwifery numbers and, in some contexts, introducing midwives as a defined sector in the health workforce are further evidence of the potential contribution of midwifery to sexual and reproductive health [14-16]. Importantly, there is significant alignment between the scope of midwifery practice and the objectives and activities of the international response to
SRH in humanitarian settings $[17,18]$. This indicates that midwives, working alongside other health professionals and providers, have the potential to meet the sexual and reproductive health needs of people in conflict and disaster contexts, as they do in stable settings.

One review examined community midwifery workforce issues such as recruitment and retention in fragile and conflict-affected countries, drawn largely from grey literature [19]. However, there are no reviews providing insight into midwives' scope of practice in the field or how this relates to international guidance.

Guidance on the potential scope of midwifery practice during humanitarian emergencies can be found in position statements released by the International Confederation of Midwives (ICM) and a report from the World Health Organization (WHO) [20]. One ICM position statement [21] encourages midwives to continue providing ongoing care and support to women during childbirth and to breastfeeding women, suggesting that the scope of practice of a midwife as defined by the ICM [22] is applicable to disaster contexts.

However, when the statements provided by ICM and WHO are compared against the roles and scope of practice of the SRH health workforce in crisis as outlined in multi-agency technical guidelines and consensus documents [17, 23-25], considerable gaps exist. Table 1 provides an overview of potential workforce roles extracted from this documentation across the emergency disaster management cycle (mitigation, preparedness, response and recovery). The table identifies six areas of workforce practice before an emergency. However, little specific guidance is provided for midwives by the ICM and WHO across these areas with gaps noted in how midwives can be best engaged in population-based health education, delivering preventative measures and mobilising community members to monitor hazards. While more information is available to guide midwives in their response efforts, considerable gaps can be seen in the recovery phase of the disaster cycle. Guidance on how midwives can contribute to sustaining, consolidating and expanding SRH services, and further developing partnerships and synergies with humanitarian and development actors to ensure comprehensive SRH care and services are provided, is absent.

While there are gaps in the guidelines to clarify the roles and scope of practice of midwives to deliver SRH in crisis settings that may constrain the contribution of midwifery, less is known about the practice of midwives in the field. Furthermore, there is ambiguity in the delineation of roles and the relationship between SRH cadres such as midwives, doctors, community health workers and lay health workers [26]. This ambiguity is partly underpinned by the inconsistent use of the term "midwife" to refer not only to fully trained and regulated midwives as defined by the ICM but in many 


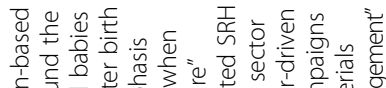

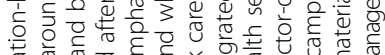
To

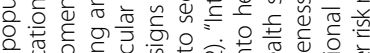

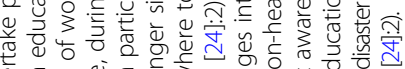

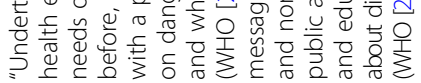

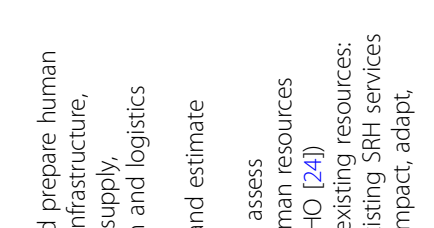

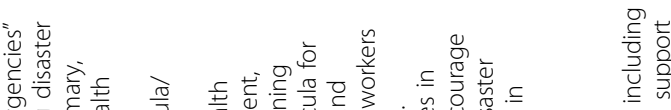

$\frac{1}{\frac{1}{3}}$

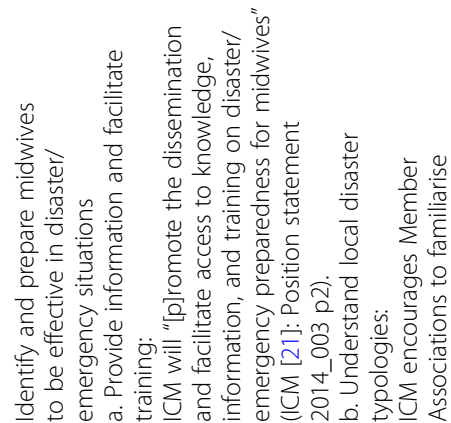

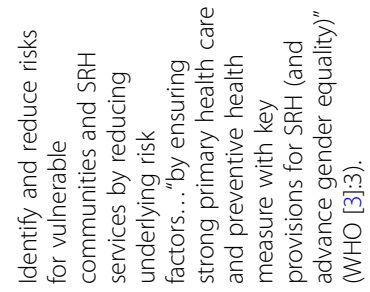

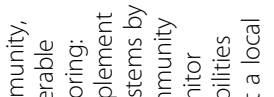

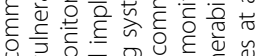

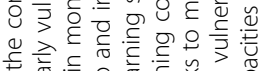

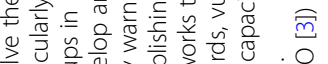

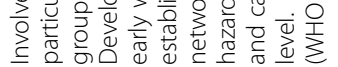

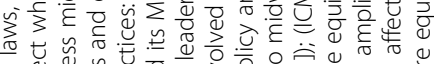

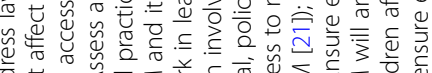

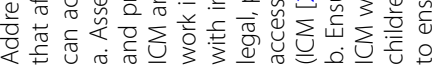

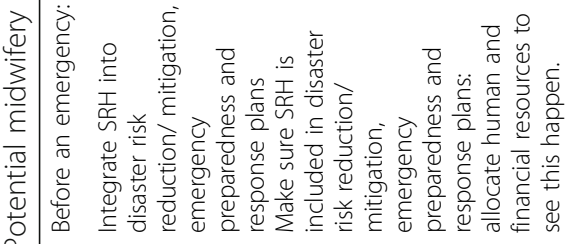

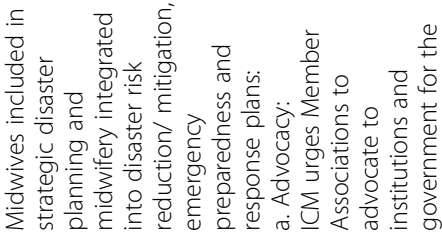

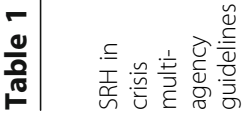

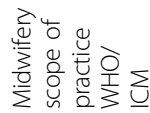




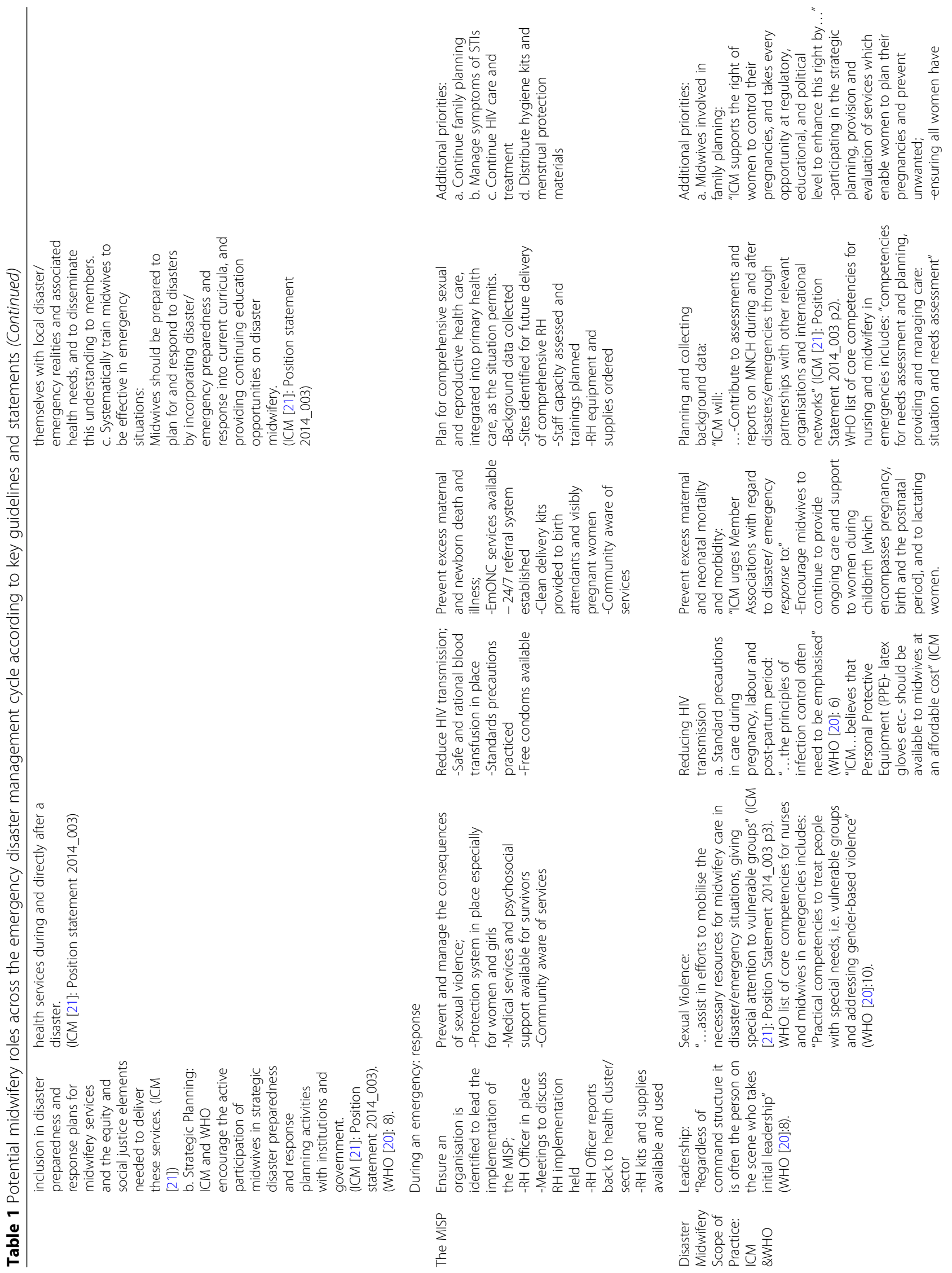




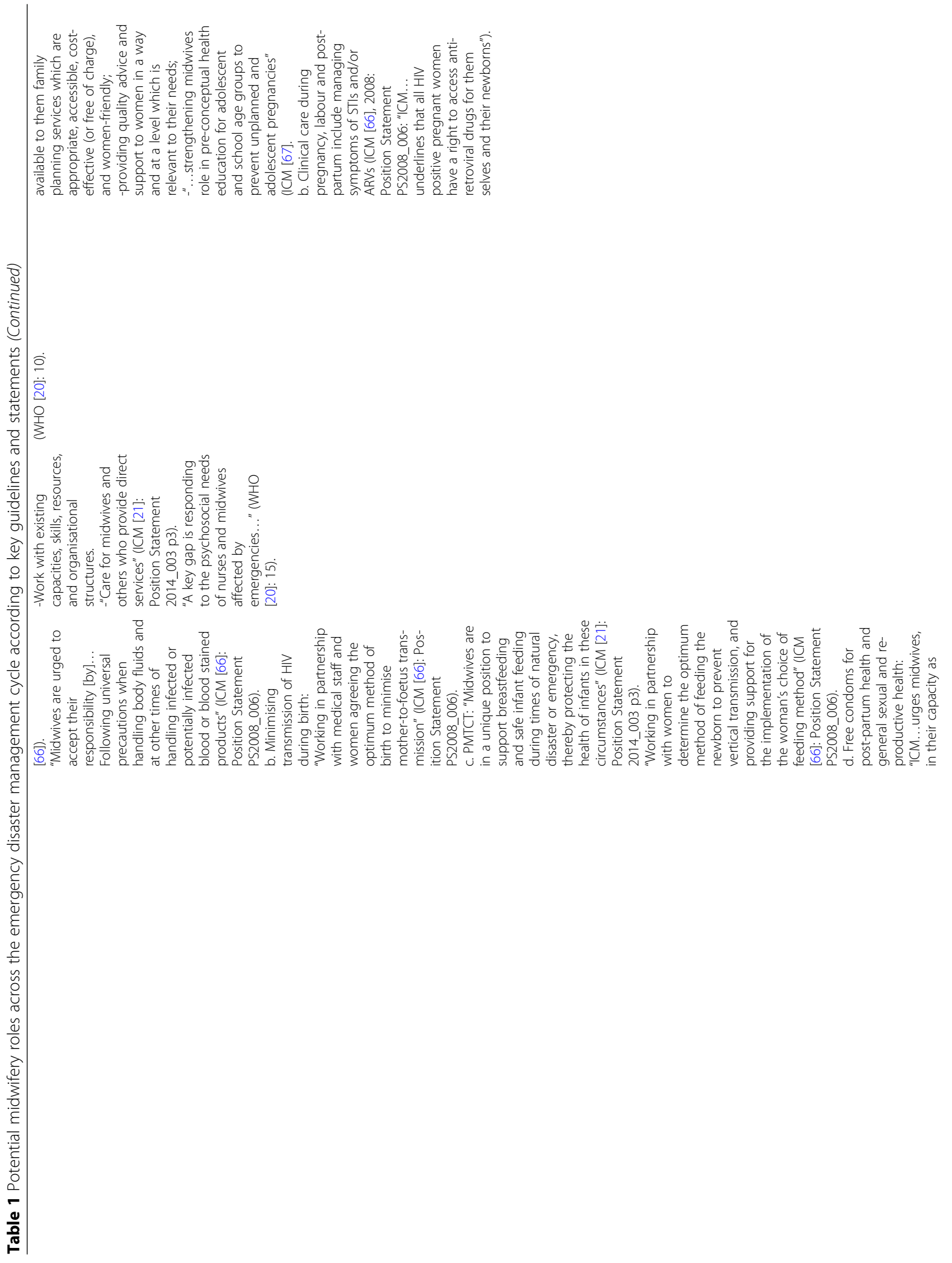



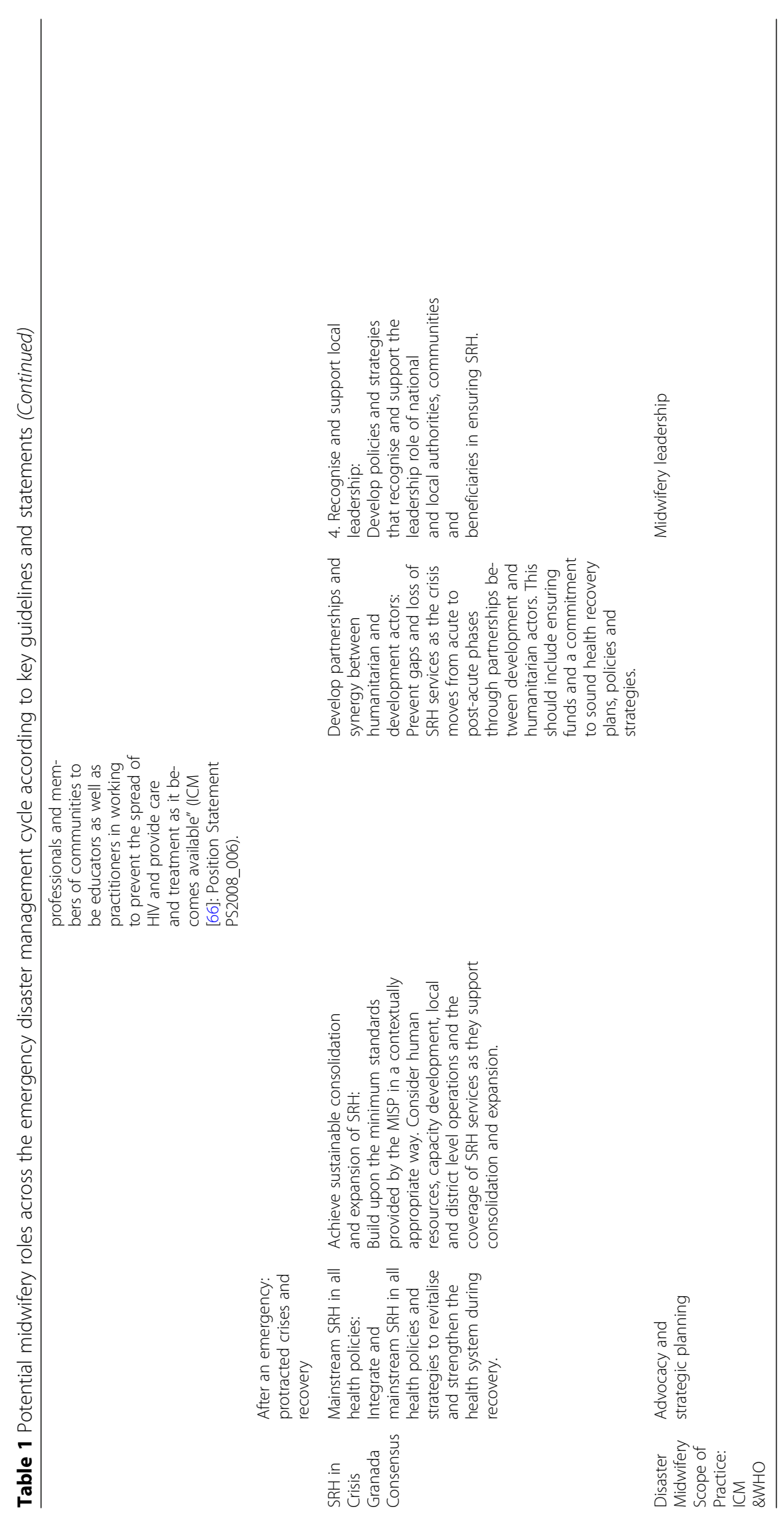
settings is used for lesser skilled workers such as auxiliary midwives or unsupported, poorly trained midwives [12, 27]. In many settings, the scope of practice of midwives is limited by the dominance of the medical profession [28-30]. In many Asian and South American countries, midwives are non-existent or have been marginalised, leading to a lack of understanding among other health care professionals and policymakers, of their scope of practice [12, 27]. Homer et al. [31] highlighted the unexploited potential of collaborative practice to improve SRH.

This lack of knowledge is problematic for the effective engagement of midwives within the broader humanitarian health sphere and for developing the disaster competency of the midwifery workforce. To begin to address this lack of evidence, we conducted a systematic review to examine the roles and relationships of midwives in humanitarian settings to inform a comprehensive approach to maximising the potential of midwives in such contexts. We sought to identify and describe the SRH care activities, services and resources midwives are involved in delivering in humanitarian emergency contexts, and how they work with other care providers to deliver health care.

\section{Methods}

\section{Study design}

The systematic review was conducted using an a priori protocol. An initial scoping exercise identified relevant databases and websites where literature on SRH in humanitarian settings, the roles of midwives in humanitarian settings, human resources for humanitarian health, disaster planning and response, and the SRH of displaced populations could be retrieved. This broad initial approach also assisted in the identification of keywords for our more focused search. As a result of the scoping exercise, four electronic databases and the websites of 33 organisations were systematically searched. These electronic bibliographic databases and websites are listed in Table 2, as are the keywords employed in our search. Reference lists of key documents were hand-searched for additional resources.

\section{Study selection and appraisal}

SRH care was defined as including those activities, services and resources outlined in the MISP [17]. We considered research pertaining to humanitarian emergency contexts, described as circumstances in which any hazard, including armed conflict, threats of natural origin, political repression, epidemics, technological hazards or a complex combination of these [32], results in a crisis of any type or scale. Key documentation was used to define areas of midwifery work in the mitigation/preparedness phase of a crisis [3, 17, 24], SRH activities in the response phase [17] and areas of action in recovery [23].

We defined the scope of practice of midwives in line with the definition provided by the ICM [22] and The State of the World's Midwifery report [18] that confirm the midwife's involvement with broader SRH.

A diverse range of research evidence was sought for this study and qualitative, quantitative and mixed methodological

Table 2 Sources and keywords

\begin{tabular}{|c|c|}
\hline Sources & Keywords \\
\hline $\begin{array}{l}\text { Electronic bibliographic databases } \\
\text { MEDLINE, Embase, Scopus and Science Direct } \\
\text { NGO websites } \\
\text { American Refugee Committee, CARE, International Consortium for } \\
\text { Emergency Contraception, International Medical Corps, International } \\
\text { Planned Parenthood Federation- The SPRINT Initiative, Ipas, The } \\
\text { International Rescue Committee, Jhpiego, John Snow, Inc., Population } \\
\text { Action International, Save the Children, Women's Refugee Commission, } \\
\text { Cambridge Reproductive Health Consultants, CHANGE: Centre for } \\
\text { Health and Gender Equity, Cordaid, Gynuity Health Projects, Medicins } \\
\text { du Monde, Inter-agency Working Group on Reproductive Health in } \\
\text { Crises, RAISE, Marie Stopes International, International Federation of } \\
\text { Red Cross and Red Crescent Societies, International Confederation of } \\
\text { Midwives and Direct Relief }\end{array}$ & \multirow[t]{3}{*}{$\begin{array}{l}\text { Midwifery OR (health care) manpower OR nurse midwives OR maternal } \\
\text { health services OR delivery, obstetrics (obstetric delivery) OR maternal } \\
\text { mortality OR midwifery workforce. } \\
\text { AND Emergencies OR emergency responders OR emergency medical } \\
\text { (health) services OR emergency medical technicians OR disaster planning } \\
\text { or civil defence OR emergency medicine OR disasters OR disaster victims } \\
\text { OR disaster medicine OR disaster planning OR crisis intervention OR relief } \\
\text { work OR refugees OR humanitarian. }\end{array}$} \\
\hline $\begin{array}{l}\text { Research organisations } \\
\text { Columbia University - The Heilbrunn Department of Population and } \\
\text { Family Health, Centre for Reproductive Rights, Emory University, Human } \\
\text { Rights Centre- University of California Berkeley School of Law, University } \\
\text { of Technology Sydney, George Washington University- Global Women's } \\
\text { Institute, Guttmacher Institute, The Centres for Disease Control and } \\
\text { Prevention }\end{array}$ & \\
\hline $\begin{array}{l}\text { United nations agencies } \\
\text { United Nations Children's Fund, United Nations High Commissioner for } \\
\text { Refugees, United Nations Population Fund, World Health Organization }\end{array}$ & \\
\hline
\end{tabular}


research included. The inclusion and exclusion criteria are presented in Table 3.

Searches were conducted between January and March 2017 and results managed using Endnote software. Two researchers (KB and $\mathrm{AD}$ ) screened titles and abstracts; full texts were obtained from relevant papers, and these were screened by two reviewers (KB and $\mathrm{AD}$ ) against the inclusion/exclusion criteria. Differences were resolved through discussion with a third reviewer (AM). The systematic review process adhered to the Preferred Reporting Items for Systematic Reviews and Meta-Analysis (PRISMA) [33] guidelines (see Fig. 1).

Eighteen papers meeting the inclusion criteria were critically appraised by three researchers using the Critical Appraisal Skill's Programme assessment tools for qualitative research [34] and Pluye et al.'s [35] scoring system for appraising mixed methods research, and the National Institute for Health and Care Excellence (NICE) guidelines [36] for survey and cross-sectional studies. Four studies were excluded from the review [37-40] as they did not adequately state research aims or methodology used.

\section{Data extraction and synthesis}

All data in the findings sections of the included 14 papers were extracted for analysis. We applied content analysis to categorise data in a systematic and replicable way [41]. The phases of the disaster or emergency management cycle represented in Table 1 provided a framework to organise emergent findings on the roles and relationships of midwives in natural, conflict and protracted crisis settings. We further explored the involvement of midwives in the delivery of SRH activities according to multi-agency guidance, WHO/ICM scope of practice, the MISP, Granada Consensus and cross cadre collaboration. Tables were created to identify and explore patterns across the findings sections of the papers under review. These were discussed by the authors to reach consensus.

\section{Findings}

Fourteen papers met our selection criteria and were included in this review (see Additional file 1 for details of included studies). Ten studies employed qualitative methods [42-50] and two were each based on quantitative [51,52] or mixed methodologies [53, 54]. As detailed in Table 4, eight papers reported findings from the response phase of the disaster, including one instance of immediate response within protracted humanitarian settings [42]. Findings were reported on the recovery phase in seven papers, and of these, one paper pertained to both the response and recovery stages of intervention [49]. Two studies closed the cycle between humanitarian and development work by detailing the roles of midwives in both preparedness and recovery $[53,54]$.

Twelve papers were from settings of conflict and two described the aftermath of natural disasters. According to the WHO regions, five studies were from the Eastern Mediterranean region, four each were from Africa and Southeast Asia, and one was from the Americas. Finally, and accounting for the multiple foci of some studies, 13 papers described the roles of midwives in providing maternal and newborn health services, three detailed this cadre's role in providing family planning, one described general reproductive health work and one discussed interventions to address sexual violence and provide emergency contraception. The characteristics of the included studies are summarised in Table 4 and discussed below according to both the three phases of the emergency management cycle and the guidance and areas of action

Table 3 Inclusion and exclusion criteria

\begin{tabular}{|c|c|}
\hline Included & Excluded \\
\hline In English & In languages other than English \\
\hline Contemporary papers (years 2007-2017) & Pre 2007 \\
\hline Papers reporting primary research (of any method) & Papers reporting other forms of research including literature reviews \\
\hline Papers pertaining specifically to the work of midwives & $\begin{array}{l}\text { Papers pertaining to clinical staff whose primary function is not to } \\
\text { provide midwifery services }\end{array}$ \\
\hline Papers which differentiate the work of midwives from other cadre & $\begin{array}{l}\text { Papers which discuss the roles of "skilled birth attendants" or "SRH staff" } \\
\text { without differentiation by cadre }\end{array}$ \\
\hline $\begin{array}{l}\text { Papers pertaining to the role of midwives in delivering and performing } \\
\text { any component of sexual and/or reproductive health outlined in the MISP, } \\
\text { clinical and/or non-clinical }\end{array}$ & Papers pertaining to general/other components of health care \\
\hline $\begin{array}{l}\text { Papers including a description of the role of midwives in delivering SRH } \\
\text { care in humanitarian emergency contexts and/or how they work with } \\
\text { other health professionals to deliver SRH care in humanitarian emergency } \\
\text { settings }\end{array}$ & $\begin{array}{l}\text { Papers in which the role(s) of midwives are not described, or where } \\
\text { involvement of midwives/ midwifery skills is recommended not } \\
\text { implemented. } \\
\text { Papers pertaining to the role of midwives in meeting the SRH needs of } \\
\text { refugee women in country of resettlement }\end{array}$ \\
\hline $\begin{array}{l}\text { Papers addressing any point in the continuum of an emergency } \\
\text { (mitigation, preparedness, response and recovery) }\end{array}$ & $\begin{array}{l}\text { Development settings and where the humanitarian setting is not directly } \\
\text { described or addressed within the paper }\end{array}$ \\
\hline
\end{tabular}



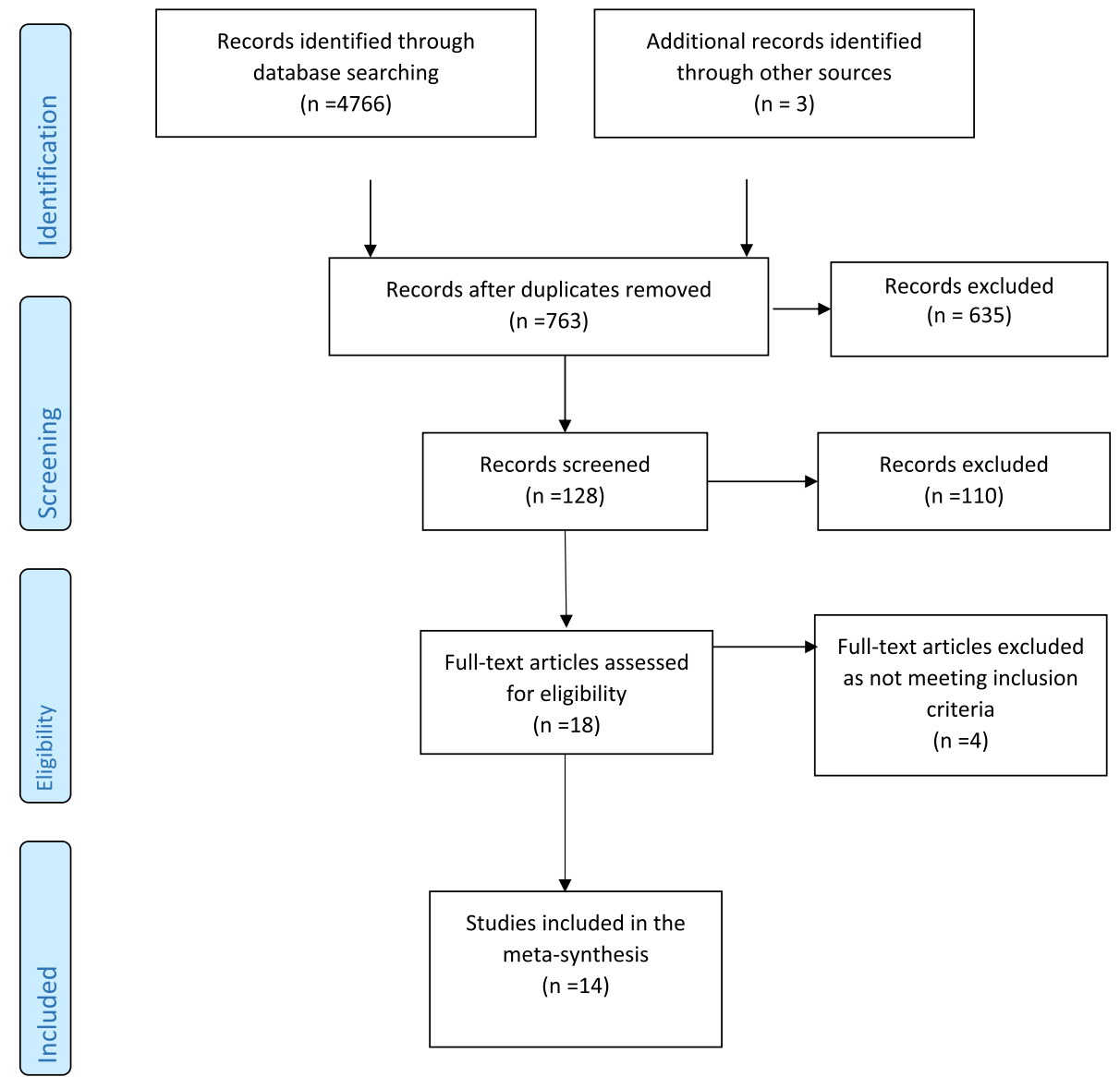

Fig. 1 Study identification and selection

associated with each according to multi-agency guidelines, the MISP and the Granada Consensus (see Table 5).

\section{Before an emergency: mitigation and preparedness}

Evidence was only found in one area of work as per the multi-agency guidelines, i.e. preparedness training of midwives (see Table 5). Two studies reported training of midwives in different humanitarian settings $[53,54]$.

In Afghanistan, Turkmani et al. [39] evaluated a pre-service competency-based midwifery curriculum comprising clinical components for antenatal, labour and postnatal care, and family planning services. Programme graduates indicated teaching was conducted in a culturally sensitive way, observed local customs and provided material support to trainee-midwives from remote areas. O'Malley Floyd [53] reported expatriate midwives, primarily from the United States of America, training local midwifery staff before and after the 2010 Haiti earthquake. The training provided by the non-profit organisation "Midwives for Haiti" was based on WHO's midwifery education modules, American College of Nurse-Midwives Lifesaving Skills manuals and two Hesperian Foundation publications [53] and aimed to address high maternal and infant mortality.

\section{During an emergency: the Minimum Initial Service Package}

We found evidence in eight papers of midwifery staff being involved in delivering routine maternal newborn care, basic emergency obstetric care, family planning and adolescent SRH services. These activities represent action in only four of the six objectives of the MISP (Table 5).

\section{MISP objective 2: Prevent sexual violence and assist survivors}

The only reference to activity related to preventing or responding to sexual violence in humanitarian settings concerned the low level of knowledge about the use of emergency contraception for both survivors of sexual violence and broader populations among midwives, on the Thailand-Burma border [45].

\section{MISP objective 4: Prevent excess maternal and neonatal mortality and morbidity}

Six of the seven papers reporting on the response phase of an emergency [43, 48-51] and a paper which detailed the response and recovery phases [49] discussed the role of midwives in providing maternal and newborn health 


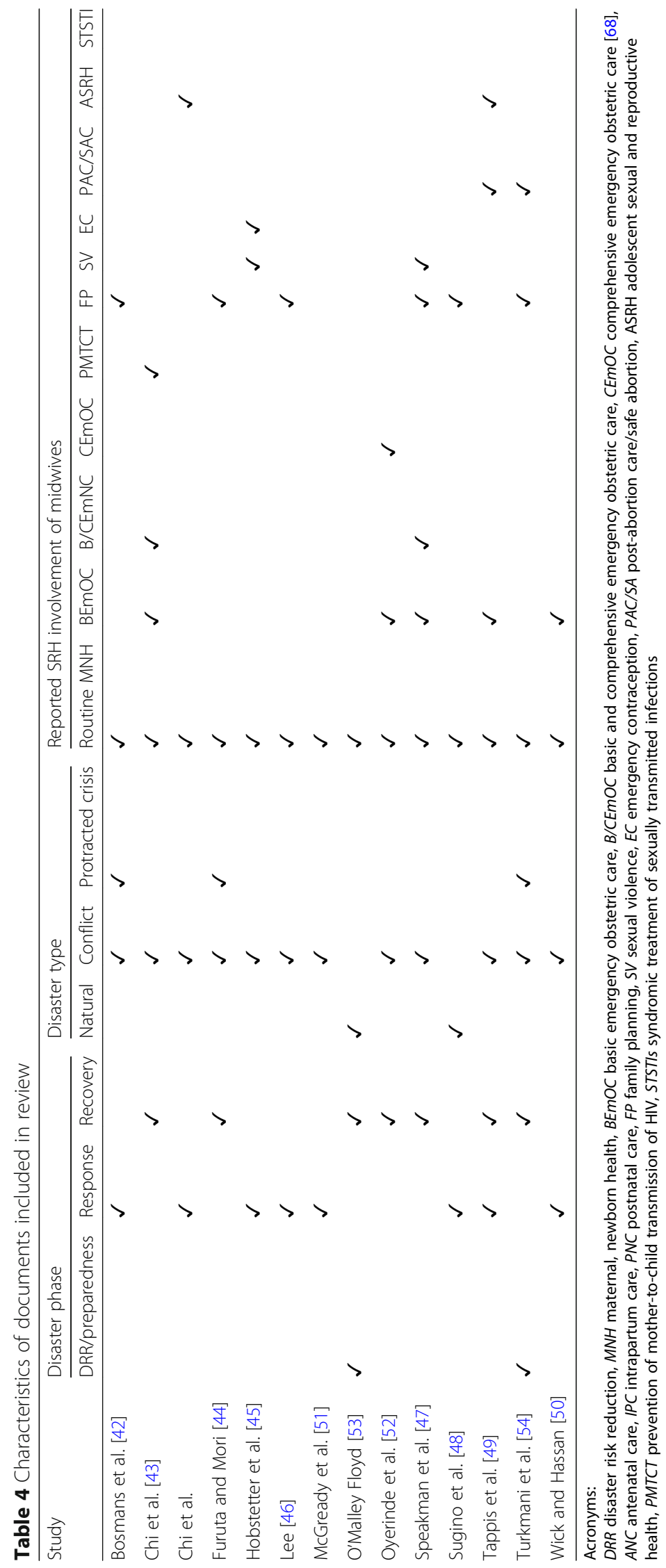




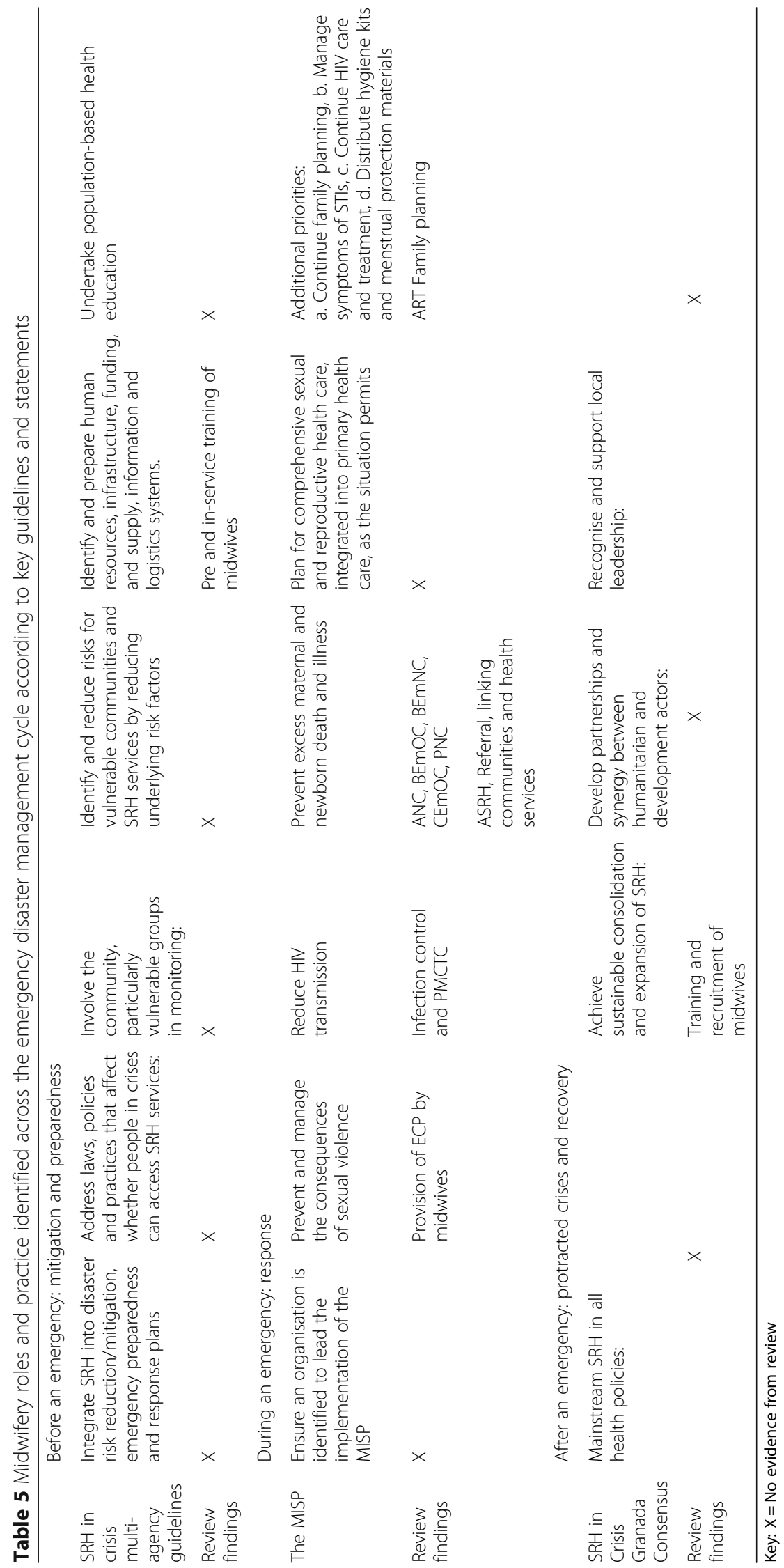


services. Midwives were reported as being involved in births at both health facilities and in women's homes $[42,46,48,50,51]$. Birthing at home was often supported by midwifery staff when access to facilities was compromised by ongoing conflict $[42,49,50]$. Examples of the challenges faced by midwives in conflict situations included in Gaza assisting a mother to birth in a house that was shaking from heavy shelling [50] and being required to stay and attend to women at a health facility during periods of curfew [42]. Tappis et al. [49] reported examples from Afghanistan of midwives lacking skills, e.g. administration of magnesium sulphate for preeclampsia and manual vacuum extraction, and lack of equipment, and both constraints on referral for women experiencing obstetric emergencies, and over-referral. No further clarification of the skills midwives applied to their roles in terms of the specifics of emergency obstetric and neonatal care signal functions was provided.

Although outside the scope of the MISP, examples of midwives working within multi-disciplinary teams in the Philippines and Thailand to provide antenatal care (ANC) during periods of conflict were described in two papers $[46,51]$. Chi et al. reported that the incursion of violence in their study site had meant that "ANC attendance was largely a luxury for many women" and that a lack of attendance for antenatal care was associated with an increase in pregnancy and birth complications.

Also beyond the scope of the minimum response outlined by the MISP, midwives were reported as being involved in postnatal care in some settings, e.g. the Philippines [46], and for adolescent women during conflict in Buruindi and Uganda. Bosman et al. [42] reported that comprehensive postnatal care was compromised in Palestine due to the ongoing conflict as curfews and checkpoints restricted staff access.

\section{Additional priorities}

Of the additional priorities of the MISP, only family planning was discussed as being part of midwives' work in the response phase of emergency contexts. Lee [46] reported that two NGOs working in conflict-affected Maguindanao made modern contraceptives and family planning services available, although the specific role of midwives among a wider team of SRH service providers was unclear. Bosmans et al. [42] explained the difficulty of providing family planning services in the longstanding humanitarian crisis in Palestine as such programmes were perceived as population control programmes.

\section{After an emergency: recovery and protracted settings}

Of the four strands of action relating to the recovery phase outlined in the Granada Consensus, evidence of only one (midwives roles in the expansion and consolidation of $\mathrm{SRH}$ ) was identified in the findings of seven papers that reported on activities in protracted emergencies and recovery after a crisis (see Table 5).

The role of midwives in both home and facility-based birth was discussed. In Burundi and Uganda, for example, while midwives and medical doctors comprise the key emergency obstetric and neonatal care providers, severe capacity gaps were noted in the provision of newborn emergency care [43]. Both Chi et al. [43] and Furuta and Mori [44] reported that midwives are trusted to attend births and to recognise the signs of obstetric emergencies and, as such, are in high demand. For women seeking care in a refugee camp in Sudan, there is a cultural preference for homebirths and midwives are not always able to leave the facility to attend [44]. In such instances, traditional birth attendants may be approached and health care from village midwives is only sought for serious conditions.

Oyerinde et al. [52] described signal functions that state-registered midwives performed in post-conflict $\mathrm{Si}$ erra Leone: administering parenteral antibiotics, oxytocics and anticonvulsants, manual removal of placenta, removal of retained products, assisted vaginal delivery and blood transfusion. However, the availability of these functions and the capacity of midwifery staff to provide them were not uniform across the study area. Chi et al. [43] reported that in post-conflict Northern Uganda, staff shortages impact on midwives' involvement in maternal and newborn health activities including antenatal care, births, the Early Infant Diagnosis room, the anti-retroviral treatment clinic, prevention of mother-to-child transmission (PMTCT) of HIV and emergency care.

Three studies discussed the training of midwives in the post-crisis recovery phase. O'Malley Floyd [53] and Turkmani et al. [54] report training of midwives before the crisis or in the aftermath of an emergency with the purpose of strengthening the health system. Speakman et al. [47] discuss the consistently positive contribution the Community Midwifery Education programme in Afghanistan has had on the reduction of maternal mortality and the increase in skilled attendance at birth.

\section{Midwifery collaboration with other health cadre}

Other health workers cited as fellow SRH service providers across the emergency management cycle include doctors, traditional birth attendants, nurses, anaesthetists, laboratory technicians, surgeons, medical assistants, maternal and child health aides, health volunteers, medical technologists, sonographers, and computer programmers.

Four papers reported that traditional birth attendants are an established source of SRH information and services, as being involved in births either at home [42, 44], at facilities [52] or at places unspecified. In all cases, 
however, inadequate numbers of skilled birth attendants had resulted in either a reliance on or re-emergence of traditional birth attendants. As explained by Bosmans et al. [42], a cut to external funding in Palestine had meant that "there was no other option than to reintegrate the dayats [traditional birth attendants] for home births and postnatal visits, even though some of them had not received any training".

The relationship between nurses and midwives was discussed in-depth in only one study. Speakman et al. [47] report that midwives and nurses worked collaboratively in the aftermath of a natural disaster in Indonesia. Midwives were required to undertake more generalist nursing duties such as the care of trauma cases in addition to their regular duties, and both nurses and midwives were tasked with increased administrative responsibilities [48]. Importantly, midwives called for clarification of the scope of practice for nurses and midwives [47]. The need for midwives to provide services not related to maternal and newborn health in emergency contexts was also reported by Turkmani et al. [54].

Speakman et al. [47] and Turkmani et al. [54] characterise the relationship between midwives and doctors by a lack of recognition and an infringement on midwives' self-perceived scope of practice. Midwives reported that doctors in Afghanistan often failed to acknowledge the skills of qualified midwives and discouraged them from performing some tasks [47]. Afghan midwives also reported feeling discriminated against by other providers, especially doctors, and were frustrated by restrictions placed upon their scope of practice [54]. Conversely, midwives in Gaza felt a sense of solidarity in their work with physicians [50].

Chi et al. [43] reported a lack of coordination between key emergency obstetric and neonatal care personnel in post-conflict Northern Uganda, particularly when needing to assemble a team of skilled providers to perform an emergency caesarean section, causing delays in important lifesaving services. At a broader level, midwives in Central Java in the aftermath of a natural disaster [48] raised concerns about coordination between midwives and nurses, and the many agencies providing disaster relief to their communities. Midwives and nurses expressed that they were not adequately informed of the activities of relief medical operations in the area [48].

\section{Discussion}

The aim of this review was to synthesise evidence regarding the roles midwives play in humanitarian contexts and their relationship with other cadres involved in the provision of SRH information and services in these settings. Across the 14 studies, we found examples of activities undertaken by midwives during the three phases of the emergency management cycle. However, as indicated in Table 5, our review clearly demonstrates that there are important gaps between the levels of guidance provided to midwives and their organisations relating to mitigation and preparedness, and recovery. Furthermore, there were substantive gaps between guidance and evidence of on-the-ground practice in all three phases of the disaster management cycle.

There is some alignment between international guidance on what is required in humanitarian settings and what the ICM/WHO asserts is the scope of midwifery practice, particularly during the response phase despite gaps in the research evidence of midwifery activity in two areas of the MISP. We did not find guidance from ICM or WHO on the potential role midwives may play in the mitigation and preparedness phase in relation to involving the community, particularly vulnerable communities, in monitoring or in reducing risks for vulnerable communities by reducing underlying risk factors, or in providing population-based health education. Evidence from two papers that reported data on preparing midwives for disasters shows that little is known about the preparation of midwives to deliver the MISP but also in terms of how midwives are involved in integrating $\mathrm{SRH}$ into disaster risk reduction/mitigation preparedness and response planning and in to laws that ensure equity and access. We did not find any guidance from ICM or WHO on the potential role midwives may play in the recovery phase in relation to achieving sustainable consolidation and expansion of $\mathrm{SRH}$, or in developing partnerships and synergy between humanitarian and development actors. The research evidence provides even less information on actual practice in the field. Given that the WHO recommends that nurses and midwives are supported to operate with a greater scope of practice in emergencies [20], this lack of guidance for important aspects of the emergency cycle is significant. Without such guidance, midwives are unlikely to deliver care to their full potential across all phases of the disaster management cycle.

In terms of collaboration and conflict with co-workers, there were three main issues: the re-emergence of traditional midwives due to shortage of skilled birth attendants, collaboration of midwives and nurses resulted in midwives assuming care that is beyond the scope of midwifery practice, and tensions between midwives and medical personnel resulting in limits to the scope of midwifery practice. Such tensions were reported in Afghanistan, possibly reflecting a lack of recognition of the role of midwives who are re-emerging as a profession in Afghanistan, as well as gender inequality $[55,56]$. We did not find any research that focussed directly on describing the role of midwives in relation to other cadres. Such research could inform future guidance for midwives operating in these contexts and seeking to 
contribute to building the resilience of their communities.

Our review found evidence of midwife shortages that led to the re-emergence of traditional birth attendants, lack of support for midwives and challenges around lack of recognition of the role and scope of midwives' practice. In many countries, these issues are not specific to emergency settings [12, 27] but reflect wider issues. There is an urgent need to scale-up all midwifery training to address shortages and to ensure that midwives have the necessary knowledge and skills to function to their full potential in non-emergency contexts as well as across all phases of emergency management. In contexts where there is a lack of midwives, a short-term solution could be to train other healthcare workers such as nurses, doctors and community health workers to provide aspects of SRH [57]. However, considerable investment is needed globally to prioritise midwifery and build capacity so that midwives are a highly competent, qualified workforce as per ICM standards [18, 27, 58].

Lessons from successful midwifery training in emergencies must be shared and scaled up, especially those reported directly from the field $[55,59]$. However, while there are excellent clinical packages available to assist the training of midwives to deliver the MISP including the SRH clinical outreach refresher training (S-CORT) [60] and $\mathrm{m}$-health applications [61], supportive strategies such as supervision are necessary to enable midwives to transfer their learning into practice [62]. Midwifery education for humanitarian training must also be incorporated into basic education and training. Leadership is necessary to achieve this. While the voices of midwives need to be represented at high-level international fora, the ICM is well positioned to support professional associations of midwives in nations across the world to strengthen quality midwifery education, care guidelines and protocols for emergencies. Midwifery associations and regulatory bodies and the Ministries of Health particularly those in LMIC can be supported by country offices of United Nations agencies such as WHO and UNFPA to better locate the roles of midwives in high-level disaster preparedness and response planning and coordination activities. The Inter-Agency Working Group for Reproductive Health (IAWG) is also an important player to assist coordination with humanitarian actors and provide technical guidance.

Implementation research is required to address the evidence gap concerning the effective delivery of midwifery-led sexual and reproductive health care in crises settings by testing workforce interventions to support midwives to deliver the Minimum Initial Service Package and strengthen collaboration and referral pathways. Workforce interventions need to be assessed alongside interventions to strengthen the health information system to generate data to inform immediate and future responses to SRH in crisis [63]. Finally, these need to be adequately costed so that financing benchmarks can be established to mobilise, accumulate and allocate money to cover the SRH needs [64].

A limitation of this review is language bias as we only included papers written in English. The search returned few papers highlighting the emerging nature of this research field and as such decisions were made to include studies that despite being methodologically "weak" provided important contextual data. The review did not allow for theorising due to the largely descriptive nature of the data. However, the use of a framework for analysis derived from the phases of emergencies and international guidelines has delivered useful insights for midwifery policy and practice in humanitarian settings.

\section{Conclusion}

This systematic review identified considerable gaps in the guidance that defines midwifery scope of practice in crises in ICM and WHO documentation particularly for the mitigation and preparedness, and recovery phases of an emergency. As shown in Table 5, there is a lack of evidence that examines midwifery interventions across the disaster management cycle, in particular, during mitigation and preparedness, and recovery phases. Research-informed guidelines and strategies are required to better align the midwifery scope of practice with the objectives of multi-agency guidelines and agreements, as well as the activities of the MISP to ensure that the potential of midwives can be acknowledged and optimised across the disaster management cycle.

\section{Additional file}

Additional file 1: Table S6. Summary of studies included in the review. (DOCX $44 \mathrm{~kb})$

\section{Acknowledgements \\ Not applicable. \\ Funding \\ This study was supported by a University of Technology Sydney Key Technology Partnership grant. The funding body had no role in the in the design of the study, collection, analysis, or interpretation of data or in writing the manuscript}

\section{Availability of data and materials}

Not applicable.

\section{Authors' contributions}

$A D$ and $A M$ conceived the study. KB led the literature search and screening with input from AD and AM. All authors appraised the studies and participated in the analysis of the data. KB led the writing of the manuscript with critical input from $A D$ and $A M$. All authors approved the final version.

Ethics approval and consent to participate Not applicable. 


\section{Consent for publication}

Not applicable.

\section{Competing interests}

The authors declare that they have no competing interests.

\section{Publisher's Note}

Springer Nature remains neutral with regard to jurisdictional claims in published maps and institutional affiliations.

\section{Author details}

${ }^{1}$ The Australian Centre for Public and Population Health Research, Faculty of Health, University of Technology Sydney, Sydney, Australia. ${ }^{2}$ Mother and Infant Research Unit, School of Nursing \& Health Sciences, University of Dundee, Scotland, UK.

Received: 19 February 2018 Accepted: 20 December 2018

Published online: 14 January 2019

\section{References}

1. UNHCR. Statistical yearbook 2015. Geneva: United Nations High Commissioner for Refugees; 2017.

2. UNFPA. UNFPA Humanitarian Action 2017. New York: UNFPA; 2017.

3. $\mathrm{WHO}$. Integrating sexual and reproductive health into health emergency and disaster risk management: policy brief. Geneva: World Health Organisation; 2012.

4. UNFPA. State of the world population report 2015: shelter from the storm a transformative agenda for women and girls in the crisis-prone world. New York: UNFPA; 2015.

5. Vu A, Adam A, Wirtz A, Pham K, Rubenstein L, Glass N, Beyrer C, Singh S. The prevalence of sexual violence among female refugees in complex humanitarian emergencies: a systematic review and meta-analysis. PLoS Curr. 2014;6. https://doi.org/10.1371/currents.dis.835f10778fd80ae031aac12d3b533ca7.

6. WRC. Minimum Initial Service Package (MISP) for Reproductive Health in Crisis Situations: A Distance Learning Module. New York: Women's Refugee Commission; 2011.

7. WHO. A universal truth: no health without a workforce. Geneva: World Health Organization; 2014

8. WHO. The World Health Report 2006 - Working together for health. Geneva: World Health Organization; 2006.

9. Casey SE, Chynoweth SK, Cornier N, Gallagher MC, Wheeler EE. Progress and gaps in reproductive health services in three humanitarian settings: mixedmethods case studies. Confl Heal. 2015;9(1):S3.

10. Roome E, Raven J, Martineau T. Human resource management in post-conflict health systems: review of research and knowledge gaps. Confl Heal. 2014;8(1):18.

11. Casey SE. Evaluations of reproductive health programs in humanitarian settings: a systematic review. Confl Heal. 2015;9(1):S1.

12. Renfrew MJ, McFadden A, Bastos MH, Campbell J, Channon AA, Cheung NF, Silva DRAD, Downe S, Kennedy HP, Malata A, et al. Midwifery and quality care: findings from a new evidence-informed framework for maternal and newborn care. Lancet. 2014;384(9948):1129-45.

13. UNFPA-ICM. Midwifery in the community: lessons learned. In: 1st International Forum on Midwifery in the Community. Hammamet: UNFPA-ICM; 2006.

14. WHO. Bangladesh expands training of midwives to improve maternal and neonatal health. Geneva: WHO; 2014.

15. WHO. Rebuilding midwifery in Sierra Leone to save the lives of women and newborns. Geneva: WHO; 2018.

16. WHO. Global strategic directions for strengthening nursing and midwifery 2016-2020. Geneva: WHO; 2016.

17. IAWG. Inter-agency field manual on reproductive health in humanitarian settings: 2010 revision for field review. New York: Inter-agency Working Group on Reproductive Health in Crises; 2010.

18. UNFPA. The State of the World's Midwifery 2014: A Universal Pathway A Woman's Right to Health. New York: UNFPA; 2014.

19. Miyake S, Speakman EM, Currie S, Howard N. Community midwifery initiatives in fragile and conflict-affected countries: a scoping review of approaches from recruitment to retention. Health Policy Plan. 2017;32(1):21-33.

20. WHO. The contribution of nursing and midwifery in emergencies. Report of a WHO consultation. Geneva: World Health Organization; 2006.
21. ICM. Position Statement: Role of the midwife in disaster/emergency preparedness PS2014 003. The Hague: International Confederation of Midwives; 2015.

22. ICM. ICM International Definition of the Midwife. The Hague: International Confederation of Midwives; 2017.

23. WHO, UNPFA, Escuela Andaluza de Salud Pública. Sexual and reproductive health during protracted crises and recovery Granada report. Geneva: WHO, UNPFA, Escuela Andaluza de Salud Pública; 2011.

24. WHO. Disaster risk management for health: Sexual and reproductive health. Geneva: World Health Orgnanization; 2011.

25. UNISDR. Sendai framework for disaster risk reduction 2015-2030. Geneva: United Nations Office for Disaster Risk Reduction; 2015.

26. Taghizadeh Z, Rad MK, Montazeri A. Basic educational needs of midwifery students for taking the role of an assistance in disaster situations: a crosssectional study in Iran. Nurse Educ Today. 2017;51:96-101.

27. ten Hoope-Bender P, de Bernis L, Campbell J, Downe S, Fauveau V, Fogstad H, Homer CS, Kennedy HP, Matthews Z, McFadden A, et al. Improvement of maternal and newborn health through midwifery. Lancet. 2014;384(9949):1226-35.

28. DeJong J, Akik C, El Kak F, Osman H, El-Jardali F. The safety and quality of childbirth in the context of health systems: mapping maternal health provision in Lebanon. Midwifery. 2010;26(5):549-57.

29. Homer CS, Foureur MJ, Allende T, Pekin F, Caplice S, Catling-Paull C. It's more than just having a baby' women's experiences of a maternity service for Australian Aboriginal and Torres Strait Islander families. Midwifery. 2012;28(4):e509-15.

30. Shaban I, Barclay L, Lock L, Homer C. Barriers to developing midwifery as a primary health-care strategy: a Jordanian study. Midwifery. 2012;28(1):106-11.

31. Homer CS, Friberg IK, Dias MAB, ten Hoope-Bender P, Sandall J, Speciale AM, Bartlett LA. The projected effect of scaling up midwifery. Lancet. 2014; 384(9948):1146-57.

32. UNISDR. UNISDR terminology on disaster risk reduction. Geneva: United Nations International Strategy on Disaster Reduction; 2009.

33. Moher D, Liberati A, Tetzlaff J, Altman DG. Preferred reporting items for systematic reviews and meta-analyses: the PRISMA statement. Ann Intern Med. 2009;151(4):264-9.

34. 10 questions to help you make sense of qualitative research [https://caspuk.net/casp-tools-checklists/]. Accessed 1 Jan 2019.

35. Pluye P, Gagnon M-P, Griffiths F, Johnson-Lafleur J. A scoring system for appraising mixed methods research, and concomitantly appraising qualitative, quantitative and mixed methods primary studies in mixed studies reviews. Int J Nurs Stud. 2009;46(4):529-46.

36. NICE. Interim methods guide for developing service guidance. London: National Institute for Health and Care Excellence; 2014.

37. Rahim HA, Wick L, Halileh S, Hassan-Bitar S, Chekir H, Watt G, Khawaja M. Health in the occupied Palestinian territory 2: maternal and child health in the occupied Palestinian territory. Lancet. 2009;373:967-77.

38. Von Roenne A, Von Roenne F, Kollie S, Swaray Y, Sondorp E, Borchert M Reproductive health services for refugees by refugees: an example from Guinea. Disasters. 2010;34(1):16-29.

39. Bouchghoul H, Hornez E, Duval-Arnould X, Philippe HJ, Nizard J. Humanitarian obstetric care for refugees of the Syrian war. The first 6 months of experience of Gynécologie sans Frontières in Zaatari refugee camp (Jordan). Acta Obstet Gynecol Scand. 2015;94(7):755-9.

40. Kottegoda S, Samuel K, Emmanuel S. Reproductive health concerns in six conflict-affected areas of Sri Lanka. Reprod Health Matters. 2008; 16(31):75-82.

41. Dixon-Woods M, Agarwal S, Jones D, Young B, Sutton A. Synthesising qualitative and quantitative evidence: a review of possible methods.J Health Serv Res Policy. 2005;10(1):45-53.

42. Bosmans M, Nasser D, Khammash U, Claeys $P$, Temmerman M. Palestinian women's sexual and reproductive health rights in a longstanding humanitarian crisis. Reprod Health Matters. 2008;16(31):103-11.

43. Chi PC, Bulage P, Urdal H, Sundby J. Barriers in the delivery of emergency obstetric and neonatal care in post-conflict Africa: qualitative case studies of Burundi and northern Uganda. PLoS One. 2015;10(9):e0139120.

44. Furuta M, Mori R. Factors affecting women's health-related behaviors and safe motherhood: a qualitative study from a refugee camp in eastern Sudan. Health Care Women Int. 2008;29(8-9):884-905.

45. Hobstetter M, Sietstra C, Walsh M, Leigh J, Foster AM. "In rape cases we can use this pill": a multimethods assessment of emergency contraception 
knowledge, access, and needs on the Thailand- Burma border. Int J Gynecol Obstet. 2015;130:E37-41.

46. Lee RB. Delivering maternal health care services in an internal conflict setting in Maguindanao, Philippines. Reprod Health Matters. 2008;16(31):65-74.

47. Speakman EM, Shafi A, Sondorp E, Atta N, Howard N. Development of the community midwifery education initiative and its influence on women's health and empowerment in Afghanistan: a case study. BMC Womens Health. 2014;14(1):111.

48. Sugino M, Dwi Hapsari E, Madyaningrum E, Haryant F, Warsini S, Takada S, Matsuo $H$. Issues raised by nurses and midwives in a post-disaster Bantul community. Disaster Prev Manag. 2014;23(4):420-36.

49. Tappis H, Koblinsky M, Winch PJ, Turkmani S, Bartlett L. Context matters: successes and challenges of intrapartum care scale-up in four districts of Afghanistan. Global Public Health. 2016;11(4):387-406.

50. Wick L, Hassan S. No safe place for childbirth: women and midwives bearing witness, Gaza 2008-09. Reprod Health Matters. 2012;20(40):7-15.

51. McGready R, Boel M, Rijken MJ, Ashley EA, Cho T, Moo O, Paw MK, Pimanpanarak M, Hkirijareon L, Carrara VI. Effect of early detection and treatment on malaria related maternal mortality on the north-western border of Thailand 1986-2010. PLoS One. 2012;7(7):e40244.

52. Oyerinde K, Harding Y, Amara P, Kanu R, Shoo R, Daoh K. The status of maternal and newborn care services in Sierra Leone 8 years after ceasefire. Int J Gynecol Obstet. 2011;114(2):168-73.

53. O'Malley Floyd B. Lessons learned preparing volunteer midwives for service in Haiti: after the earthquake. J Midwifery Women's Health. 2013;58(5):558-68.

54. Turkmani S, Currie S, Mungia J, Assefi N, Rahmanzai AJ, Azfar P, Bartlett L. 'Midwives are the backbone of our health system': lessons from Afghanistan to guide expansion of midwifery in challenging settings. Midwifery. 2013;29(10):1 166-72.

55. Currie S, Tappis H. Ending preventable maternal deaths: Advancing proven efforts to prevent postpartum hemorrhage. In: 17th Annual Meeting of the Inter-agency Working Group IAWG on Reproductive Health in Crises. Athens; 2017.

56. Filby A, McConville F, Portela A. What prevents quality midwifery care? A systematic mapping of barriers in low and middle income countries from the provider perspective. PLoS One. 2016;11(5):e0153391.

57. Dawson AJ, Buchan J, Duffield C, Homer CS, Wijewardena K. Task shifting and sharing in maternal and reproductive health in low-income countries: a narrative synthesis of current evidence. Health Policy Plan. 2013;29(3):396-408.

58. ICM. Education, Regulation and Association. The Hague: International Confederation of Midwives; 2017.

59. Cornier N. Midwifery is not just a quick fix: Strategic planning in northern Syria. In: 17th Annual Meeting of the Inter-agency Working Group IAWG on Reproductive Health in Crises. Athens; 2017.

60. Tran NT, Harker K, Yameogo WME, Kouanda S, Millogo T, Menna ED, Lohani JR, Maharjan O, Beda SJ, Odinga EA. Clinical outreach refresher trainings in crisis settings (S-CORT): clinical management of sexual violence survivors and manual vacuum aspiration in Burkina Faso, Nepal, and South Sudan. Reprod Health Matters. 2017;25(51):103-13.

61. Lund S, Boas IM, Bedesa T, Fekede W, Nielsen HS, Sørensen BL. Association between the safe delivery app and quality of care and perinatal survival in Ethiopia: a randomized clinical trial. JAMA Pediatr. 2016;170(8):765-71.

62. Beek K, Dawson A, Whelan A. A review of factors affecting the transfer of sexual and reproductive health training into practice in low and lowermiddle income country humanitarian settings. Confl Heal. 2017;11(1):16.

63. Pyone T, Dickinson F, Kerr R, Boschi-Pinto C, Mathai M, Nvd B. Data collection tools for maternal and child health in humanitarian emergencies: a systematic review. Bull World Health Organ. 2015;93:648-58.

64. Woodward A, Sondorp E, Witter S, Martineau T. Health systems research in fragile and conflict-affected states: a research agenda-setting exercise Health Res Policy Syst. 2016;14(1):51

65. ICM. Health of Women and Children in Disasters: PS2011 008 V2017. The Hague: International Confederation of Midwives; 2011.

66. ICM. Human Immunodeficiency Virus and Acquired Immunodeficiency Syndrome (HIV and AIDS): PS2008_006 V2014. The Hague: International Confederation of Midwives; 2008.

67. ICM. Planned pregnancies and parenthood: PS2011_016. The Hague: International Confederation of Midwives; 2011.

68. WHO, UNFPA, UNICEF, AMDD. Monitoring emergency obstetric care: a handbook. Geneva: World Health Organization; 2009. http://whqlibdoc. who.int/publications/2009/9789241547734_eng.pdf?ua=1.

\section{Ready to submit your research? Choose BMC and benefit from}

- fast, convenient online submission

- thorough peer review by experienced researchers in your field

- rapid publication on acceptance

- support for research data, including large and complex data types

- gold Open Access which fosters wider collaboration and increased citations

- maximum visibility for your research: over $100 \mathrm{M}$ website views per year

At BMC, research is always in progress.

Learn more biomedcentral.com/submissions 